\title{
The impact of the socio-economic policies of states on population migration as a factor in the sustainable development of territories
}

\author{
Lidiya Manukovskaya*, Marina Zhukova, and Vladimir Mashukov \\ Altai State University, Pr. Lenina, 61, 656049 Barnaul, Russia
}

\begin{abstract}
The article examines population migration as a factor in ensuring sustainable development of the territory. The research analyzed socioeconomic and migration indicators of the Russian Federation and of the Republic of Kazakhstan. The features and general trends of migration processes and socio-economic development of these countries are revealed. The research of the relationships between migration indicators and socioeconomic indicators of countries was carried out using SPSS 20 based on the pair correlation method. An analysis of the relationships revealed a strong correlation of socio-economic indicators with indicators of population migration. The results of the research can be used to develop areas of socio-economic policy of the Russian Federation and of the Republic of Kazakhstan.
\end{abstract}

\section{Introduction}

Ensuring the sustainable development of territories is of great importance in the modern conditions of the growing instability of the world economy. Sustainable development of territories is determined by its labor resources, the quantity and quality of which changes under the influence of migration. Thus, population migration is one of the most important factors affecting the sustainable development of the territory.

Population migration is a property of the social reality of society, acting as a complex process of the population's response to the changing situation of an evolving social life, consisting of many events that encourage people to change their place of residence [1].

Population migration has a direct impact on the socio-economic and demographic development of the country. At the same time, the country's socio-economic policy affects the nature and indicators of population migration $[2,3]$.

The socio-economic policy of the state can be considered as a form of conscious influence on the socio-economic sphere of society with a view to changing it [4]. Socio-economic policy has an impact on increasing the rate of production of goods and services, ensuring financial stability, improving conditions for entrepreneurship and business activity, increasing the welfare and living standards of the population, which has a direct impact on migration processes. Research and identification of the relationships between socio-

\footnotetext{
* Corresponding author: manukovskaya@rb.asu.ru
} 
economic indicators and migration processes in the country can help create conditions for reducing the outflow of population to foreign countries and attracting citizens from other countries in accordance with the needs of the national economy, which will ensure sustainable development.

\section{Materials and methods}

The main goal of the work is to research of the impact of socio-economic policies of states on population migration as a factor in sustainable development of territories. Socio-economic indicators are the result of the country's socio-economic policy. The impact of socioeconomic indicators of the country's development on the processes of population migration is considered in the studies of the authors: E. Lee [5], E.S. Vakulenko, N.V. Mkrtchyan, K.K. Furmanov [6], E. Fong [7], Yu. A. Logunova [8], R. Ramos [9], S. V. Taskaeva [10], A. A. Tkachenko [11], P.G. Abdulmanapov [12], R. Bhagat [13]. The following indicators were considered as the main indicators of the country's socio-economic development: average pension, average monthly nominal wage, unemployment rate, GDP per capita and consumer price index and others. The study examined the relationships between migration indicators and socio-economic indicators of the Russian Federation and the Republic of Kazakhstan for the period from 2007 to 2018 .

When processing empirical data, the results were obtained: the Pearson correlation coefficient $r$, the number of pairs of values used and the probability of error. The relationships between migration and socio-economic indicators were analyzed using SPSS 20 pair correlation method. In order to evaluate the criterion of the relationship between the variables and analyze the steady correlations, statistical tools were used: the correlation coefficient (r) and significance level (p) [14].

The closer the relationship between indicators is determined using the correlation coefficient, which can have a value from "minus" 1 to "plus" 1 . With a direct relationship between the indicators, the correlation coefficient is greater than 0 , and with an inverse less than 0 . Than greater the absolute value of the correlation coefficient, that closer the relationship between indicators. If the value of the correlation coefficient lies in the range from 1 to 0.9 in absolute value, a very strong correlation dependence is noted. If the value of the correlation coefficient lies in the range up to 0.9 in absolute value - a high correlation dependence; up to 0.7 - average; up to 0.5 - weak correlation dependence. The degree of significance of the correlation between the studied phenomena is determined by certain threshold values.

For the practical purposes of this work, we used a correlation threshold value of 0.7 and a significant level of significance $(\mathrm{p}<0.01)$.

The analysis of indicators was carried out on the data presented on the official websites Statistics Committee of the Ministry of National Economy of the Republic of Kazakhstan and official website of the Federal Statistics Service of the Russian Federation [15,16].

\section{Results and Discussion}

One of the most important indicators characterizing the migration situation in the country is the net migration rate. It should be noted that the net international migration in the Russian Federation, the Republic of Kazakhstan in the period 2007-2011 had a positive value, but the values of the net migration rate was wave-like (figure 1). So, a synchronous increase in the values of the net migration rate was observed in the Russian Federation and in the Republic of Kazakhstan in 2008-2009. There was a simultaneous decrease in this indicator in these countries in 2011-2018. The peak value of the net migration rate was for Russia (2.24 
$\%$ ) in 2011 , then the indicator under consideration slightly decreased to $1.68 \%$ in 2015 . The smallest values of the net migration rate were noted in the Russian Federation (0.85\%) in 2018. The net migration rate were negative in the Republic of Kazakhstan since 2012, the value of the net migration rate decreased from (-0.7 \%o) to (-1.58 \%o) from 2014 to 2018 (Fig. $1)$.

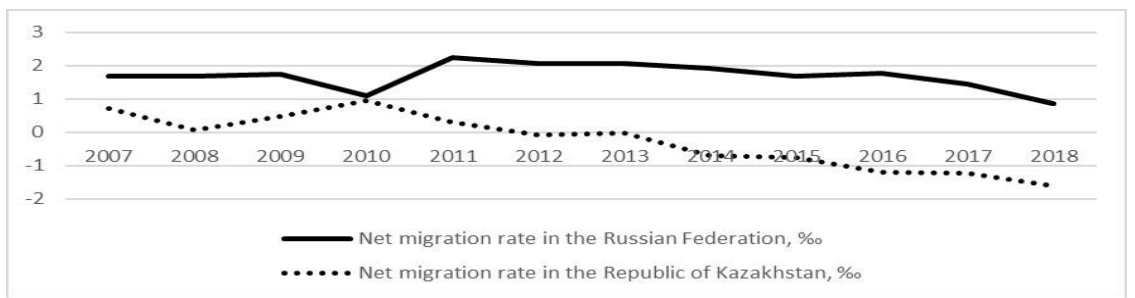

Fig. 1. Change of the net migration rate in the Russian Federation and in the Republic of Kazakhstan for the period 2007-2018, (\%o)

The values of the net migration rate of the Russian Federation exceed the value of the given indicator in the Republic of Kazakhstan.

Let us turn to the analysis of the structure of migration flows in the countries under consideration.

The number of immigrants from the CIS countries to the Russian Federation increased in 2.97 times in 2018 compared with 2010, and in 1.94 times compared with 2007 (Fig. 2). The proportion of immigrants from the CIS countries in the total number of immigrants in Russia for the analyzed period amounted to more $87 \%$. The largest number of immigrants was observed from the following countries: Ukraine, Uzbekistan, Kazakhstan, Tajikistan, Azerbaijan, Armenia.

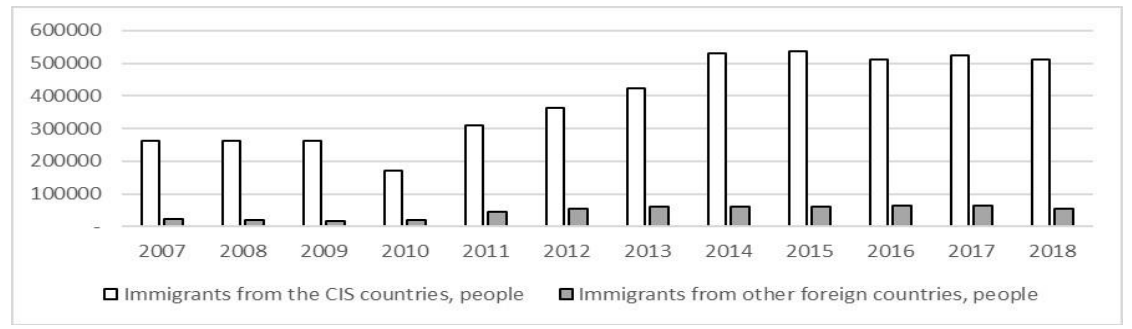

Fig. 2. Change of the number of immigrants in the Russian Federation in the period 2007-2018, people

The largest number of immigrants from the CIS countries in the Republic of Kazakhstan was observed in 2007 (Fig.3). The number of immigrants from the CIS countries to the Republic of Kazakhstan decreased significantly (3.19 times) in 2010-2016.

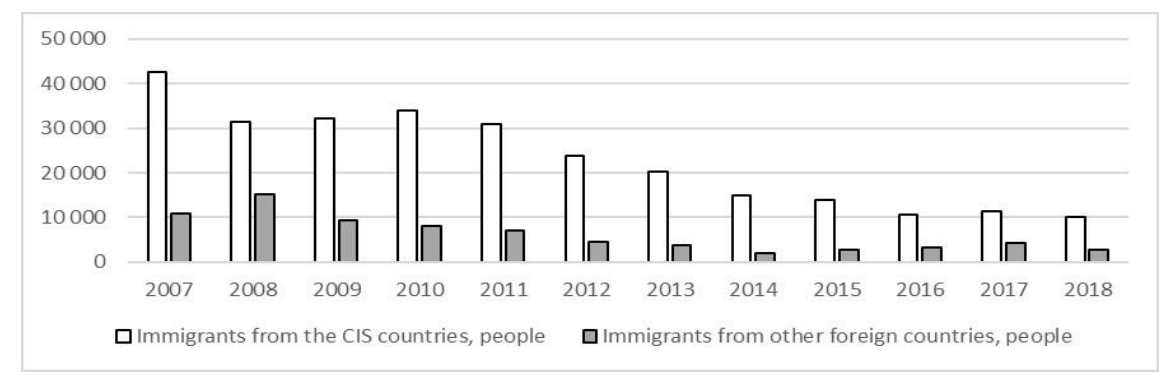

Fig. 3. Change of the number of immigrants in the Republic of Kazakhstan in the period 2007-2018, 
people

Thus, CIS citizens predominated in the structure of immigrants in the countries under review in the reporting period (over 67\%).

Consider the features of changes of the number of emigrants in the Russian Federation and the Republic of Kazakhstan in the period 2007-2018 (Fig. 4,5). A number of general trends should be noted:

- The predominance of citizens from the CIS countries in the structure of emigrants (for Russia their share exceeds $61 \%$, for Kazakhstan - 89\%).

- There was a decrease in the number of citizens emigrating from the countries in question to the CIS countries and non-CIS countries in 2007-2009.

- All the countries analyzed were characterized by an increase in emigrants to the CIS countries in 2013-2015 and 2016-2018; in general, the growth rate of the number of emigrants to the CIS countries in 2018 compared to 2007 was $1242.66 \%$ for Russia.

- There was a significant increase in emigration for permanent residence in non-CIS countries (in the Russian Federation - 3.48 times, in the Republic of Kazakhstan - 1.55 times in 2018 compared to 2007).

The largest emigration of citizens from the Russian Federation was noted to Ukraine, Kazakhstan, Uzbekistan, Tajikistan, Armenia and Kyrgyzstan in the period 2007-2018 (Fig. 4).

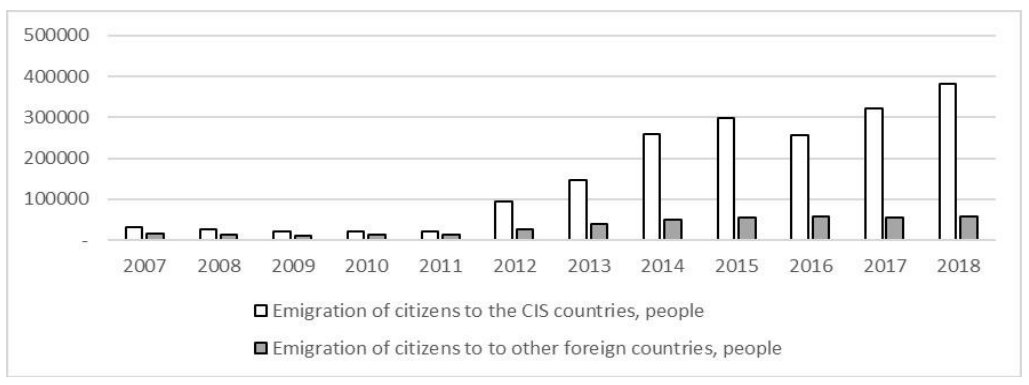

Fig. 4. Change of the number of emigrants in the Russian Federation in the period 2007-2018, people

The largest number of emigrants in the Republic of Kazakhstan in the analyzed period was observed in 2008 (45287 people). Intensive emigration from Kazakhstan to Russia and Germany was observed in the period 2007-2018. More than 600 people annually leave for permanent residence from the Republic of Kazakhstan to the Republic of Belarus from 2007 to 2015 (Fig. 5).

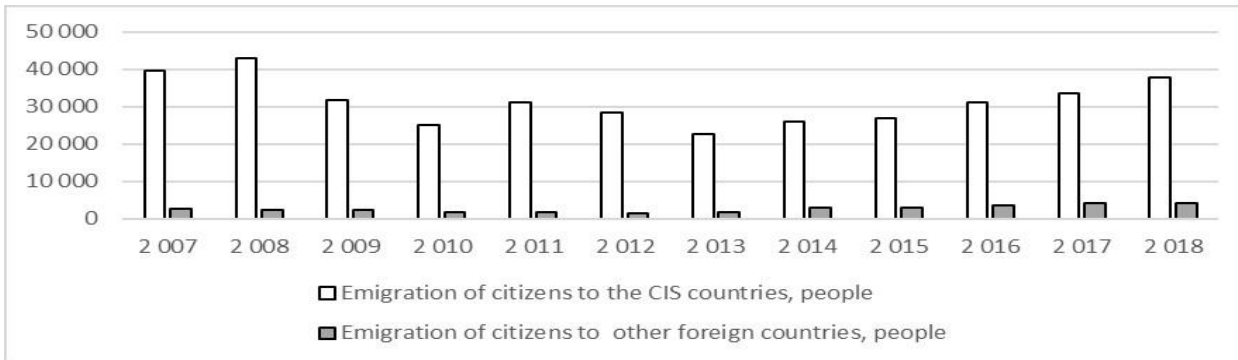

Fig. 5. Change of the number of emigrants in the Republic of Kazakhstan in the period 2007-2018, people

Thus, it can be noted that the migration situation in the countries under consideration is different, but there are some general trends. Between the CIS countries there is an intensive migration exchange. The number of emigrants leaving the Republic of Kazakhstan for 
permanent residence in the CIS countries increased in 2007-2018, and the number of emigrants leaving for the CIS countries exceeds the number of immigrants coming from the CIS countries in 2011-2018. Migration processes at the level of international exchange in the countries under consideration are becoming more extensive and intensive, especially in the Russian Federation. Therefore, the research of the factors of socio-economic development that affect migration processes in the studied countries is relevant.

Let us turn to the consideration of socio-economic factors affecting migration processes in countries. To compare a number of indicators by country, they are given in US dollars.

The average pension in US dollars in the Russian Federation was significantly higher than the average pension in the Republic of Kazakhstan in the period 2008-2013 as shown in Figure 6. At the same time, the average pension in US dollars in Russia decreased and was less than the same indicator in Kazakhstan in 2013-2015. An increase in the average pension in US dollars is observed in the Russian Federation in 2016-2018, while the average pension is higher in Russia than in Kazakhstan. The lowest average pension was recorded in the Republic of Kazakhstan (97.1 US dollars) in 2007, and the highest average pension was observed with the Russian Federation (307 US dollars) in 2013. It should be noted the general trends: there was an increase in average pension in all countries in 2009-2010, in 2011-2013 and in 2016-2018, and her decline in 2013-2015.

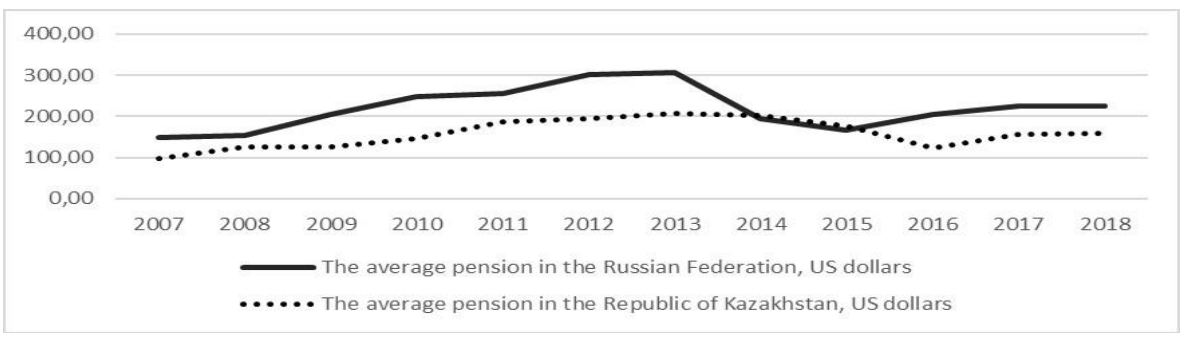

Fig. 6. Change of the average pension in the Russian Federation and the Republic of Kazakhstan for the period 2007-2018, US dollars

Consider the changes in the average monthly nominal wage of employees in these countries in 2007-2018.

The average monthly nominal wage of employees in the Russian Federation exceeded the same indicators of the Republic of Kazakhstan for the analyzed period, with the exception of 2015 (Fig.7). It should be noted general trends: there was an increase in average monthly nominal wage of employees in all countries in the period 2011-2013 and in 2016-2018, and her decline in 2014-2015. The highest average monthly nominal wage of employees was recorded in Russia (936.3 US dollars) in 2013 and the lowest in the Republic of Kazakhstan (417.6 US dollars) in 2016.

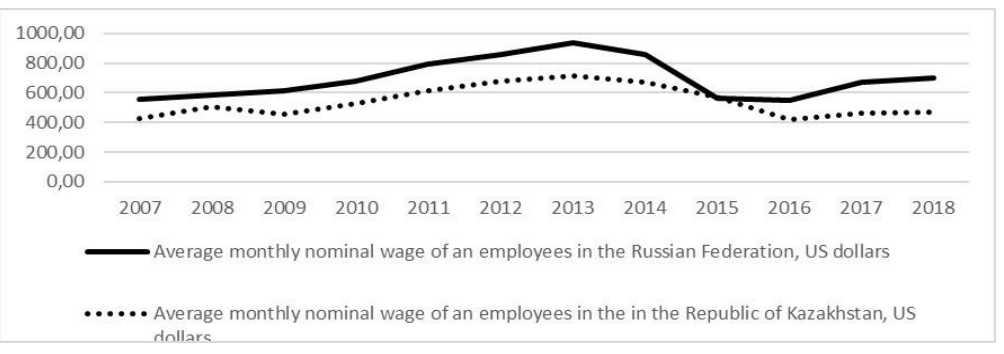

Fig. 7. Change of the average monthly nominal wage of employees in the Russian Federation and the Republic of Kazakhstan for the period 2007-2018, USD

The ratio of the average monthly nominal wages of employees to the living wage is used 
as the most important tool for assessing the living standards of the population in terms of income and consumption.

The smallest values of the ratio of the average monthly wage of employees to the subsistence minimum were recorded in the Russian Federation in the analyzed period (Fig. 8). The smallest ratio of employees' wages to living wage was recorded in 2008 and amounted to 3.18. The highest values of this indicator were recorded in the Republic of Kazakhstan (6.16 times) in 2016. The values of the ratio of the average monthly wage of employees to the subsistence level in the Republic of Kazakhstan significantly exceed the similar indicators of the Russian Federation in the analyzed period.

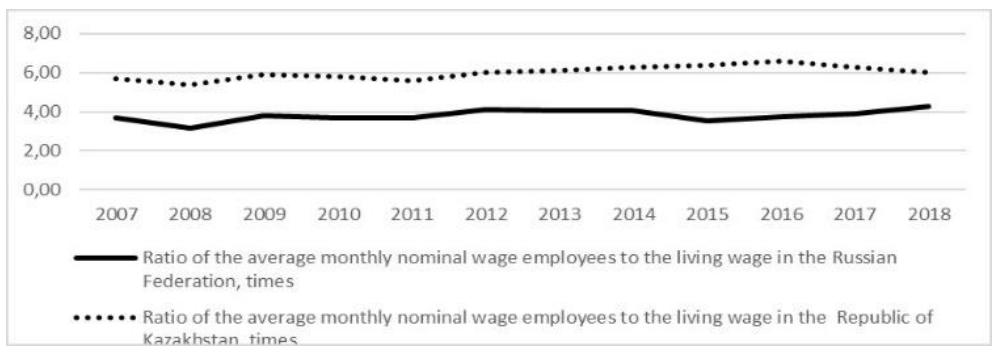

Fig. 8. The ratio of the average monthly nominal wage of employees to the living wage in the Russian Federation and the Republic of Kazakhstan for the period 2007-2018, times

Recommended pension should be at least $40 \%$ of the average monthly wage in the economy in accordance with the 102nd Convention of the International Labor Organization "On minimum standards of social security" [18]. This convention is currently ratified only in the Russian Federation. The highest ratio of average pension to average monthly nominal wage of employees was observed in the Russian Federation (37.36\%) in 2016 (Fig.9). This indicator ranged from $22.67 \%$ to $37.36 \%$ in Russia in the analyzed period. The lowest ratio of average pension to average monthly nominal wage of employees was in Kazakhstan compared to Russia in the reporting period, with the exception of 2014 and 2017-2018. An increase in this indicator was observed in all countries in 2008-2010 and in 2014-2015.

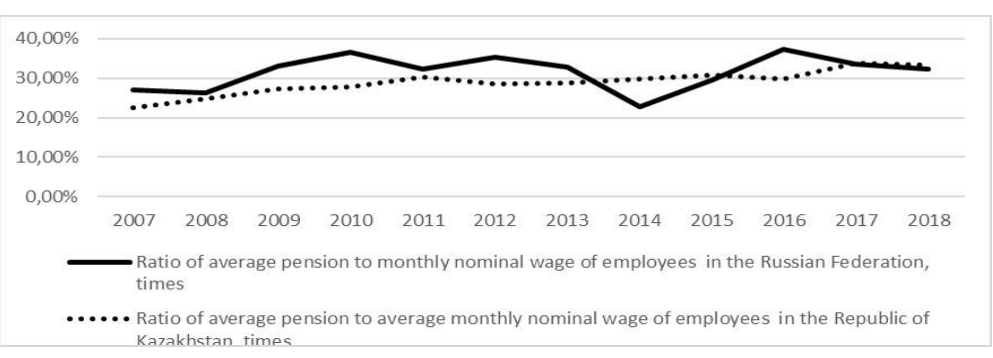

Fig. 9. The ratio of the average pension to the average monthly nominal wage of employees in the Russian Federation and in the Republic of Kazakhstan for the period 2007-2018, \%

The unemployment rate has a significant impact on migration processes in countries. The unemployment rate in the analyzed period was undulating (Fig. 10). The highest unemployment rate was recorded in the Russian Federation (8.3\%) in 2009. The lowest value was in Russia (4.8\%) in 2018. It should be noted general trends: there was a decrease in unemployment rate in all countries in 2009-2012 and in 2016-2018, and growth in 20142015. These countries have close values of the unemployment rate in 2012-2018. 


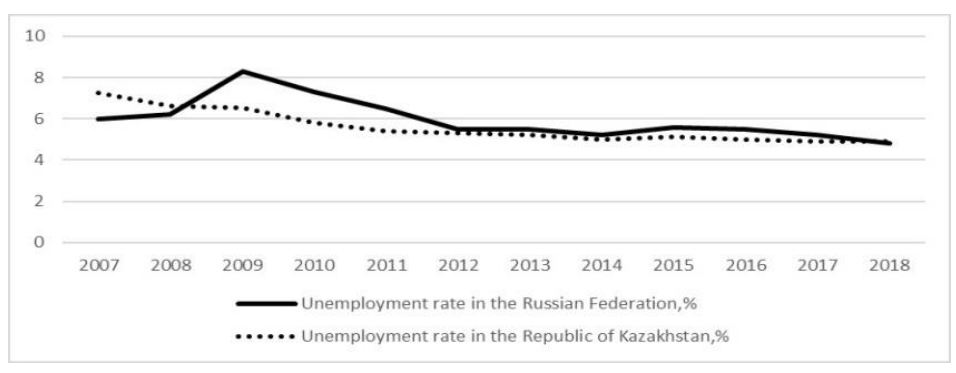

Fig. 10. Change of the unemployment rate in the Russian Federation and in the Republic of Kazakhstan for the period 2007-2018, \%

Figure 11 presents the change of the consumer price index in the Russian Federation and in the Republic of Kazakhstan, for the period 2007-2018. The consumer price index slightly increased in all the countries under review in 2007-2008, it decreased in 2016-2017. The values of the consumer price index did not differ much in all the analyzed countries in the periods 2009-2013.

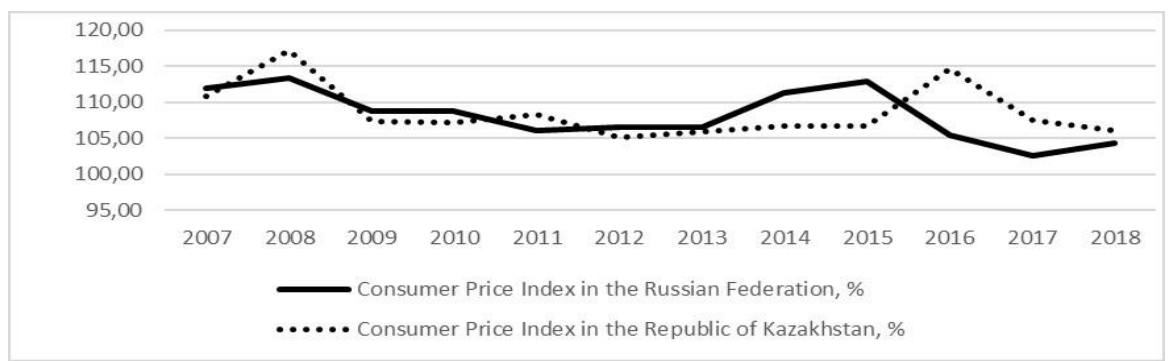

Fig. 11. Change of the consumer price index in the Russian Federation, and in the Republic of Kazakhstan for the period 2007-2018, \%

Change of the level of GDP per capita in the Russian Federation, the Republic of Kazakhstan for the period 2007-2018 presented in figure 12.

A number of trends should be noted:

- GDP per capita growth was in all analyzed countries in 2007-2008, in 2009-2013, in 2016-2018.

- GDP per capita decreased in all countries under consideration in 2008-2009, 20132016.

- The highest value of GDP per capita was in the Russian Federation (15991.6 US dollars) in 2013, in the Republic of Kazakhstan (13890.8 US dollars).

- The smallest value was in Russia (8562.8 US dollars) in Kazakhstan (7165.22 US dollars) in 2009.

- GDP per capita was significantly higher in the Russian Federation than the indicators of the Republic of Kazakhstan in the analyzed period, with the exception of 2015 (Fig. 12). 


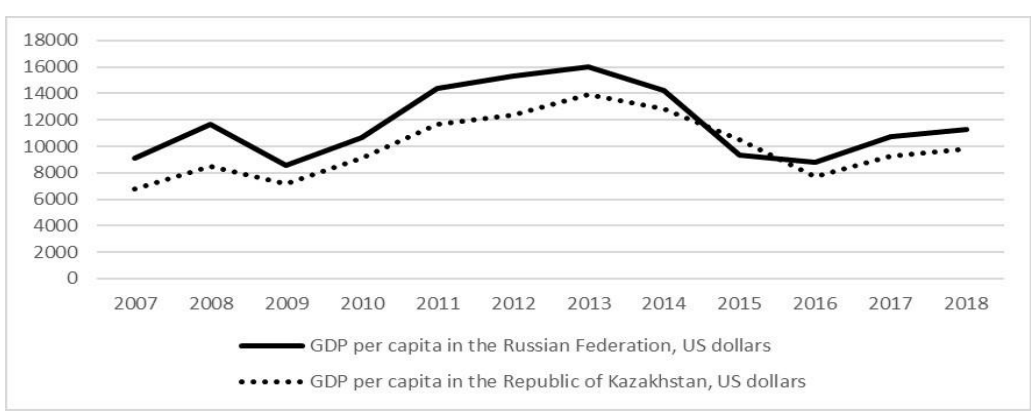

Fig. 12. Change of the GDP per capita in the Russian Federation and in the Republic of Kazakhstan for the period 2007-2018, USD USA

First, we consider the results of the correlation analysis of indicators for Russia.

We have identified strong opposite correlations of socio-economic indicators with:

1. Migration indicator (immigration):

- Immigrated in the Russian Federation and proportion of women in the total population $(\%)(\mathrm{r}=-0.758 ; \mathrm{p}=0.004)$.

- Immigrated in the Russian Federation and public spending on education $(\%)(r=-0.840$; $\mathrm{p}=0.001)$.

- Immigrated in the Russian Federation and unemployment rate $(\%)(\mathrm{r}=-0.789 ; \mathrm{p}=$ 0.002 ).

- Immigrated in the Russian Federation and mortality rate $(\% 0)(r=-0.878 ; p=0.000)$.

Since 2010, an increase in population immigration correlates with a decrease in unemployment, mortality rate, proportion of women in the total population and public spending on education. This is with some degree of probability due to the fact that since 2010, in most cases, a young able-bodied male population has come to Russia, able to fill the niches of the employment market. Education costs during this period are reduced. These indicators correlate with between themselves. It can be assumed that this relationship is a consequence to the concept of demographic development of the Russian Federation.

2. Migration indicator (emigration):

- Emigration from the Russian Federation and mortality rate $(\% 0)(r=-0.860 ; p=0.000)$.

- Emigration from the Russian Federation and public spending on healthcare $(\%)(\mathrm{r}=$ $0.767 ; \mathrm{p}=0.004)$.

- Emigration from the Russian Federation and proportion of women in the total population $(\%)(\mathrm{r}=-0.834 ; \mathrm{p}=0.001)$.

- Emigration from the Russian Federation and public spending on education $(\%)(\mathrm{r}=$ $0.867 ; \mathrm{p}=0,000)$.

- Emigration from the Russian Federation and unemployment rate $(\%)(\mathrm{r}=-0.758 ; \mathrm{p}=$ $0.004)$.

The increase in the outflow of the population is correlated with a decrease in the unemployment rate, the share of women in the total population, the mortality rate, government spending on health and government spending on education.

This is partly due to the fact that net migration of men is greater than that of women in the analyzed period, with the exception of 2015 and 2018. Those who leave without being able to find work in accordance with their professional level are most likely to have the status of unemployed, as well as those who are at risk of death (health problems, bad habits, environmental conditions of the territory of residence) and occupational risk.

Public spending on education and public spending on healthcare during this period are declining according to the concept of demographic development of the Russian Federation.

We have identified strong direct correlations of socio-economic indicators with:

1. Migration indicator (immigration): 
- Immigrated in the Russian Federation and commissioning of residential buildings per capita(sq. m. of total area) $(r=0.952 ; \mathrm{p}=0.000)$.

- Immigrated in the Russian Federation and average annual exchange rate(US dollar / Russian ruble) ( $\mathrm{r}=0.800 ; \mathrm{p}=0,002)$.

- Immigrated in the Russian Federation and proportion of children in the total population $(\%)(\mathrm{r}=0.911 ; \mathrm{p}=0.000)$.

2. Migration indicator (emigration):

- Emigration from the Russian Federation and commissioning of residential buildings per capita (sq. m. of total area) $(r=0.907 ; \mathrm{p}=0.000)$.

- Emigration from the Russian Federation and average annual exchange rate (US dollar / Russian ruble) ( $\mathrm{r}=0.891 ; \mathrm{p}=0,000)$.

- Emigration from the Russian Federation and proportion of children in the total population $(\%)(r=0.979 ; \mathrm{p}=0.000)$.

Two opposing migration indicators (emigration and immigration) correlated with the same socio-economic characteristics (commissioning of residential buildings per capita, sq. $\mathrm{m}$. of total area, average annual exchange rate (US dollar / Russian ruble), proportion of children in the total population). This fact makes it possible to assume that the changes selected socio-economic parameters are not primary factors which reduce emigration or increase immigration. Due to the specificity of the development of migration processes, these relationships are observed.

For example, an increase in the proportion of children in the total population during immigration, indicates the entry of immigrants along with children, and / or of reproductive age. And in the case of emigration, the increase in the proportion of children in the total population is due to the fact that they migrate without children (single people; young people without children; go abroad only to earn money) and / or are elderly people.

The increase in average annual exchange rate (US dollar / Russian ruble) and the increase in immigration flows to Russia are explained by the worse conditions for the economic development of the territory of the migrants' former residence and the possibility of exchanging the national currency for rubles to support families, close relatives of the territory of the migrants' former residence. In the case of emigration, assessing the development of the Russian economy as unstable and the search for more economically developed territories.

Relationship between the dynamics of commissioning of residential buildings per capita (sq. m. of total area) and migration indicators (emigration and immigration) is clearly traceable. However, the positive dynamics of commissioning of residential buildings per capita cannot have a decisive influence on migration processes since the level of housing provision of the country's population is much lower than in developed countries, and in the structure of commissioning of apartments there is a shift towards one-room apartments.

Consider the results of the correlation analysis of indicators for Kazakhstan.

We have identified strong opposite correlations of socio-economic indicators with:

1. Migration indicator (net migration rate):

- The net migration rate and ratio of the average pension to the living wage (US dollar) $(\mathrm{r}=-0.836 ; \mathrm{p}=0.001)$.

- The net migration rate and commissioning of residential buildings per capita (sq. m. of total area) $(\mathrm{r}=-0.909 ; \mathrm{p}=0.000)$.

- The net migration rate and average annual exchange rate (US dollar / Kazakh tenge) ( $\mathrm{r}=$ $-0.889 ; \mathrm{p}=0.000$ ).

- The net migration rate and proportion of children in the total population $(\%)(\mathrm{r}=-0.957$; $\mathrm{p}=0.000)$.

A decrease in the net migration rate correlates with an increase in ratio of the average pension to the living wage, commissioning of residential buildings per capita, average annual exchange rate (US dollar / Kazakh tenge), proportion of children in the total population. The 
obtained results indicate active actions by the state aimed at regulating socio-economic processes in order to reduce emigration and ensure reproduction of the population. It can be assumed that these actions are likely to achieve this goal, since there is an increase in the proportion of children in the total population.

2. Migration indicator (immigration):

- Immigration in the Kazakhstan and ratio of the average pension to the living wage, US dollar $(\mathrm{r}=-0.949 ; \mathrm{p}=0.000)$.

- Immigration in the Kazakhstan and ratio of the average monthly nominal wage of employees to the living wage, US dollar $(r=-0.842 ; p=0.001)$.

- Immigration in the Kazakhstan and commissioning of residential buildings per capita, sq. $\mathrm{m}$. of total area $(\mathrm{r}=-0.756 ; \mathrm{p}=0.004)$.

- Immigration in the Kazakhstan and average annual exchange rate, US dollar / Kazakh tenge, $(r=-0.797 ; p=0.002)$.

A decrease in population immigration correlates with an increase in ratio of the average pension to the living wage, ratio of the average monthly nominal wage of employees to the living wage, commissioning of residential buildings per capita, average annual exchange rate (US dollar / Kazakh tenge). These correlations also reflect the active actions of the state aimed at regulating migration processes by creating favorable and stable socio-economic conditions.

We have identified strong direct correlations of socio-economic indicators with:

1. Migration indicator (migration rate):

- The net migration rate, $\%$ and unemployment rate $(\%)(\mathrm{r}=0.732 ; \mathrm{p}=0.007)$.

- The net migration rate, $\%$ and mortality rate $(\%)(r=0.860 ; p=0.000)$.

- The net migration rate, $\%$ and proportion of women in the total population $(\%)(\mathrm{r}=0.797$; $\mathrm{p}=0.002)$.

The decrease in immigration correlates with a decrease in unemployment rate, mortality rate, proportion of women in the total population.

2. Migration indicator (immigration):

- Immigration in the Kazakhstan and unemployment rate $(\%)(\mathrm{r}=0.917 ; \mathrm{p}=0.000)$.

- Immigration in the Kazakhstan and export as\% of GDP ( $r=0.872 ; \mathrm{p}=0.000)$.

- Immigration in the Kazakhstan and import as\% of GDP ( $\mathrm{r}=0.813 ; \mathrm{p}=0.001)$.

- Immigration in the Kazakhstan and mortality rate $(\% 0)(r=0.979 ; \mathrm{p}=0.000)$.

- Immigration in the Kazakhstan and proportion of women in the total population (\%) $(\mathrm{r}=0.965 ; \mathrm{p}=0.000)$.

The decrease in immigration correlates with a decrease in unemployment rate, mortality rate, proportion of women in the total population, as well as a decrease in export as \% of GDP and import as $\%$ of GDP.

The decrease in the level of imports and exports of goods and services per capita affects the estimate of the territory as economically less favorable for living, which leads to a decrease in immigration from other countries.

A negative value of the net migration rate in Kazakhstan indicates the predominance of emigration of the population. This circumstance to some extent causes a change in the sex and age structure of the population and leads, firstly, to an aging workforce, and secondly, which is typical for Kazakhstan, to a decrease in the share of women in the total population.

The emigration of the population, especially its able-bodied part, leads to a decrease in the level of education and professional qualifications of the personnel of enterprises and in the economically active part of the population. 


\section{Conclusions}

The research revealed the specifics of population migration in the Russian Federation and the Republic of Kazakhstan in the period 2007-2018. Using SPSS 20 the pair correlation method allowed us to analyze the relationships between indicators of migration and socio-economic indicators of countries and to identify strong correlations.

It should be noted that to ensure the sustainable development of the territory, it is important to analyze the impact of the state's socio-economic policy on migration processes. This will allow to regulate migration flows, minimizing the negative social and economic consequences for the country and increasing the positive aspects of attracting foreign labor to meet the needs of the growing economy of the territory in labor resources.

\section{References}

1. M.V. Zhukova, L.A. Manukovskaya, NovaInfo (2017)

2. N.E. Petrovskaya, L.V. Kutsegreeva, A.A. Maksaev, I.A. Raevich, International Journal of Economics and Business Administration, 204 (2019)

3. D.N. Shaikin, Economic analysis: theory and practice, 57 (2013)

4. D.A. Gaynanov, Theory and mechanisms of modern public administration: textbook. Allowance, 157 (2020)

5. E.A. Lee, Demography (1966)

6. E.S. Vakulenko, N.V. Mkrtchyan, K.K. Furmanov, XII International Scientific

Conference on the Development of Economy and Society. In four books. Book 1, 336 (2012)

7. E. Fong, K. Shibuya, X. Chen, International migration (2019)

8. Yu.A. Logunova, Scientific and methodological electronic journal Concept, 253 (2018)

9. R. Ramos, Journal of Geographical Systems (2019)

10. S.V. Taskaeva, Transbaikal state university journal, 176 (2007)

11. A.A. Tkachenko, A.B. Ginoyan, Statistics Issues, 53 (2018)

12. P.G. Abdulmanapov, MEPS: Management, Economics, Politics, Sociology, 54 (2019)

13. R. Bhagat, International Journal of Global Environmental Issues (2011)

14. A. Buyul, P. Zöfel, SPSS: the art of information processing. Analysis of statistical data and the restoration of hidden patterns (2005)

15. The official website Statistics Committee of the Ministry of National Economy of the Republic of Kazakhstan (2020), http://stat.gov.kz/

16. The official website of the Federal Statistics Service of the Russian Federation (2020), https://www.gks.ru/

17. International Labor Organization Convention No. 102 on Minimum Standards of Social Security (1952), https://base.garant.ru/502541190/ 